\title{
6. IN SITU LARGE-SCALE ELECTRICAL RESISTIVITY OF OCEAN CRUST, HOLE 504B ${ }^{1}$
}

\author{
R. P. Von Herzen, Woods Hole Oceanographic Institution, Woods Hole, Massachusetts \\ T. J. G. Francis, Institute of Oceanographic Sciences, Wormley, Godalming, Surrey, United Kingdom \\ and \\ K. Becker, Scripps Institution of Oceanography, La Jolla, California
}

\section{INTRODUCTION}

The achievement of deep penetration $(562 \mathrm{~m})$ of seafloor basalts at Hole 504B, near the Costa Rica Rift $\left(1^{\circ}\right.$ $\left.13.63^{\prime} \mathrm{N}, 83^{\circ} 43.81^{\prime} \mathrm{W}\right)$, on DSDP Legs 69 and 70 presented a rare opportunity to examine the structure of young $(6 \mathrm{~m} . \mathrm{y}$.) oceanic crust. In addition to the recovery of samples for laboratory studies, an extensive suite of downhole logs and experiments was carried out at this site, for two main purposes: (1) to allow reliable deductions about the nature of the entire section of penetrated crust, because recovery of samples was far from complete $(\sim 25 \%)$; (2) to probe the physical state of rock around the drilled hole on a scale of tens of meters to kilometers. Information on the latter large-scale phenomena at Hole 504B were provided mainly by the oblique seismic experiment, utilizing a bore-hole seismometer (Stephen, this volume), and by the large-scale-electrical-resistivity experiment described below.

The highly porous and permeable nature of young ocean crust has been shown in many studies over the past decade to be almost ubiquitous. Locally variable and low mean heat flow over much of the ocean floor (Anderson, et al., 1977), especially that with the youngest ages (e.g., Green et al., 1981) is presently the most persuasive but indirect evidence for vigorous hydrothermal circulation. Electrical measurements are a potentially sensitive method to investigate the nature of porosity and permeability in ocean crust, because the electrical conductivity of the pore fluid (sea water) is two to four orders of magnitude greater than the intrinsic conductivity of the host rocks at crustal temperature $\left(\leq 300^{\circ} \mathrm{C}\right)$. The recent availability of bore holes in the oceanic crust allows these parameters and their functional dependence on depth to be investigated most directly.

Logging of electrical conductivity and other parameters in crustal rocks has been carried out on several DSDP legs (e.g., Kirkpatrick, 1979). As might be expected, most of these studies show that the in situ conductivity is much greater than that measured on samples recovered by coring, implying in situ porosity significantly greater than that represented by core-sized samples. This result in turn implies that much of the porosity is present on a scale greater than hand-sized speci-

\footnotetext{
${ }^{1}$ Cann, J. R., Langseth, M. G., Honnorez, J., Von Herzen, R. P., White, S. M., et al. Init. Repts. DSDP, 69: Washington (U.S. Govt. Printing Office).
}

mens. The large-scale distributions of porosity and permeability are obviously critical for understanding of hydrothermal circulation, crustal structure, and the origin of ocean crust. The first measurements of large-scale oceanic crustal electrical resistivity have been reported by Francis (1981) on DSDP Leg 60, although measurements were limited to the uppermost sedimentary layer. The experiment carried out on DSDP Leg 70 extended over nearly the entire basalt section drilled at Hole 504B, which represents half or more of the seismic Layer 2 thickness at this site (Stephen, this volume). The largescale measurements are compared with standard electrical-logging measurements made in the same hole.

\section{DESCRIPTION OF EXPERIMENT}

The equipment utilized in this experiment is essentially the same as that described by Francis (1981), except that a cable with longer electrode spacings was deployed (Fig. 1). The increased electrode spacing allows greater penetration of current away from the hole, so that the resistivity measurements are representative of a thicker annulus of rock around it. This increased radius of penetration is obtained at the price of reduced vertical resolution, i.e., the greater the electrode spacing, the smoother the resistivity measurements with depth down the hole. The relatively great depth of basement penetration at this site allowed us to take advantage of a wide electrode spacing without sacrificing significant detail down-hole, or precluding a significant number of measurements because of limited hole length.

Before the measurements down-hole, the $\mathrm{Ag}-\mathrm{AgCl}$ electrodes had been electrically connected to each other and immersed in sea water about 1 week. About $1 \mathrm{hr}$ after disconnecting them from each other, but before attaching them to the insulated cable, all voltages between electrodes were less than a few tenths millivolts. The relative voltages during the measurements down-hole were occasionally an order of magnitude larger, and slowly varying, perhaps because of the effects of temperature gradients. The reversal of current polarity on each measurement allowed such voltage differences to be determined and removed by calculation. As described in Francis (1981), all voltages observed on the ship have been corrected for measured resistances in the logging and insulated cables, and for the series and parallel resistances of the potentiometric recorders and associated equipment, to deduce those voltages that existed at the electrodes down-hole. 


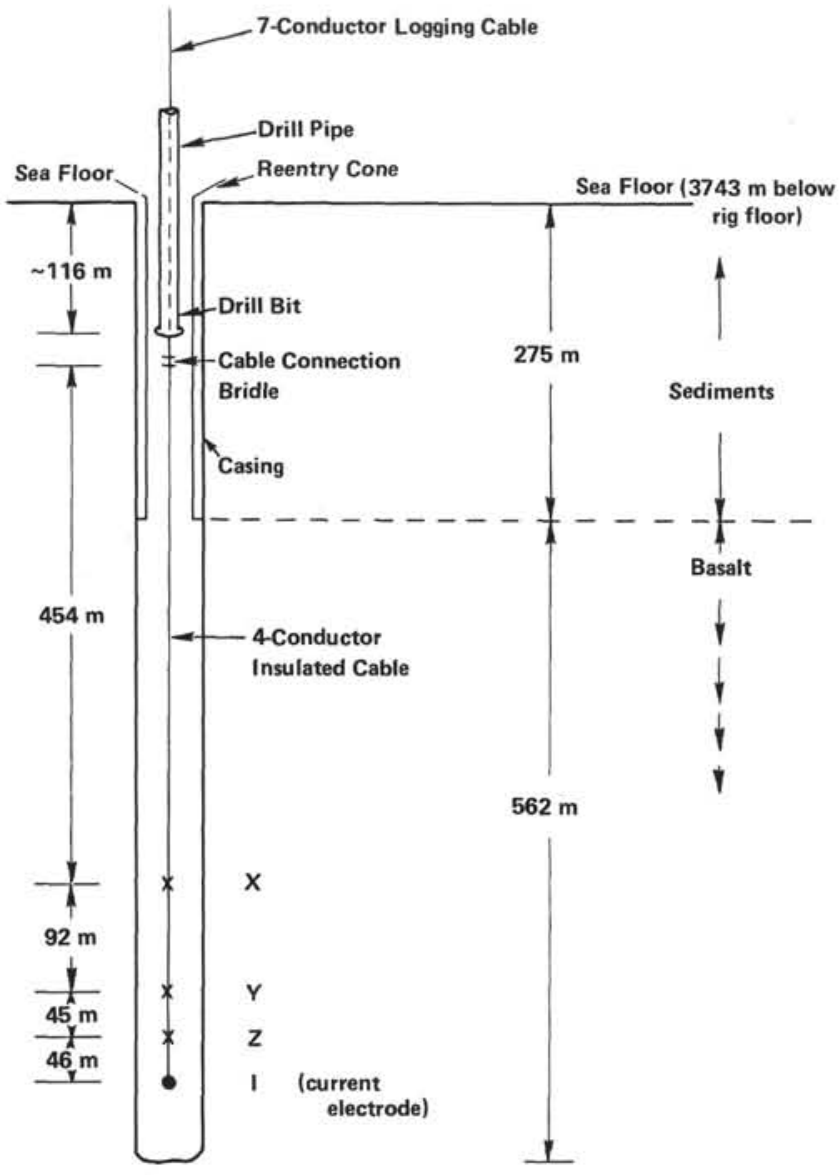

Figure 1. Configuration of the large-scale-electrical-resistivity experiment used in Hole 504B. Direct current was provided through the current electrode I and the sea (viz., the exposed logging cable armor), and voltages were detected via potential electrodes $X, Y$, and $Z$.

Measurements were carried out at discrete depth intervals over a period of lowering, then raising, of the electrode array over the length of the uncased basalt section of the drill hole. During the lowering phase, useful measurements were carried out at even 50-meter depth intervals between 3350 and 3650 meters (depth below rig floor of connection between logging and insulated cables), and during raising at even 25 -meter intervals between 3650 and 3250 meters. At each depth level, the current ( $\sim 6.0 \mathrm{amp})$ was applied continuously for about $10 \mathrm{sec}$ to allow the voltage between electrodes, $V_{y x}$ and $V_{z y}$, to stabilize. The current was then reversed and applied for a similar duration at the same depth (Fig. 2). Voltages were determined to a precision of 0.1 mvolt, and the adopted voltage is the mean value with opposite current polarities.

The apparent resistivities are calculated from the formula derived by Francis (1981):

$$
\varrho_{z y}=\frac{2 \pi V_{z y}}{I\left[\frac{z}{h^{2}-z^{2}}-\frac{y}{h^{2}-\mathrm{y}^{2}}\right]},
$$

where $h, y, z$ are the depths of the current $(I), \mathrm{Y}$ and $Z$ electrodes below the sea floor, respectively. A corre-

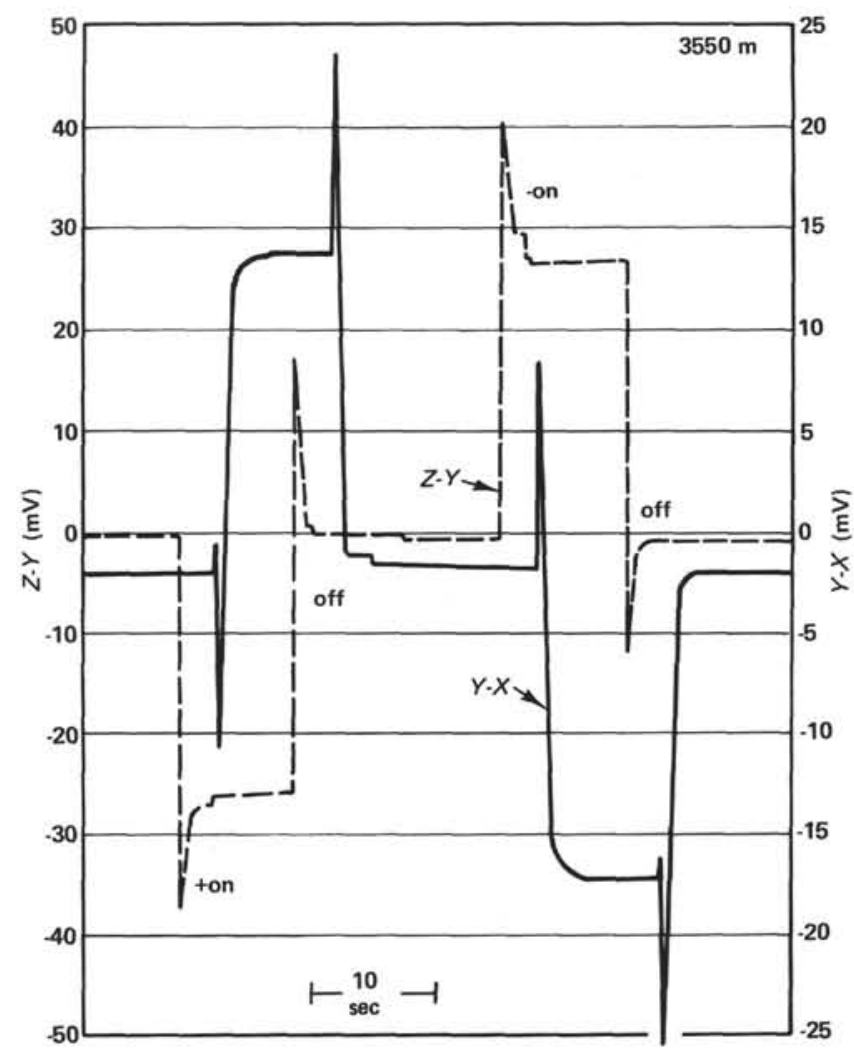

Figure 2. Line drawing of recorded data from the large-scale experiment at 3550 meters below rig floor. Current is first applied in one polarity, then reversed, voltages between electrode pairs being recorded as indicated.

sponding formula is used for $\varrho_{y x}$. The calculated apparent resistivities with depth are given in Table 1, and are plotted in Figure 3. The plotted depths are those of the lowermost electrode below the sea floor for each of the respective electrode pairs. This was done because the voltage variations are most sensitive to changes of resistivity where the current density is highest (the lower electrode closest to the current source).

\section{RESULTS}

It is seen from Figure 3 that the variation of apparent resistivity with depth is reasonably consistent for both the descending and ascending phases of the measurements, with the exception of a few values determined at the beginning of the deployment, when the experimental procedures were not stabilized. Also, the two electrode arrays of different lengths show approximately the same variations of resistivity with depth. The shorter array $(z-y, 45-\mathrm{m}$ separation) shows a greater range of values and greater variability than the longer array $(y-x, 92-\mathrm{m}$ separation), as would be expected theoretically. The longer array is a better filter for the small-scale variability in resistivity.

For the depth interval 420 to 520 meters sub-bottom, $\varrho_{y x}$ may be significantly lower than $\varrho_{z y}$. This may indicate that porosity near the hole $(<50 \mathrm{~m}$ distant $)$ is lower than that farther away at this depth. Note that for the uppermost two values of $\varrho_{y x}$ measured during the ascending phase of the experiment, the $x$-electrode is 
Table 1. Hole 504B large-scale-resistivity experiment.

\begin{tabular}{cccc}
\hline & $\begin{array}{c}\text { Measured } \\
\text { Voltages } \\
(\mathrm{mV})\end{array}$ & $\begin{array}{c}\text { Calculated } \\
\text { Resistivity } \\
\text { (ohm-m) }\end{array}$ \\
$\begin{array}{c}\text { Depth } \\
(\mathrm{m})\end{array}$ & $V_{\mathrm{yx}}$ & $V_{\mathrm{zy}}$ & ezy $\quad$ eyx \\
\hline
\end{tabular}

Descending

$\begin{array}{lllrr}3350 & 21.2 & 26.3 & 4.9 & 7.8 \\ 3400 & 17.8 & 26.5 & 4.9 & 6.7 \\ 3450 & 26.1 & 74.4 & 13.8 & 9.7 \\ 3500 & 33.1 & 70.9 & 13.3 & 12.5 \\ 3550 & 32.5 & 64.2 & 12.0 & 12.3 \\ 3600 & 29.2 & 45.0 & 8.5 & 11.1 \\ 3650 & 24.3 & 44.2 & 8.3 & 9.3\end{array}$

Ascending

\begin{tabular}{rrrrr}
3625 & 25.2 & 41.2 & 7.8 & 9.6 \\
3600 & 30.0 & 43.8 & 8.3 & 11.5 \\
3575 & 29.1 & 56.6 & 10.7 & 11.1 \\
3550 & 31.8 & 66.5 & 12.5 & 12.1 \\
3525 & 34.0 & 53.4 & 10.0 & 12.8 \\
3500 & 35.2 & 70.8 & 13.3 & 13.3 \\
3475 & 33.6 & 82.2 & 15.4 & 12.7 \\
3450 & 25.1 & 76.8 & 14.3 & 9.4 \\
3425 & 22.3 & 63.6 & 11.9 & 8.4 \\
3400 & 22.2 & 49.8 & 9.3 & 8.4 \\
3375 & 23.5 & 63.8 & 12.0 & 8.9 \\
3350 & 21.8 & 62.4 & 11.6 & 8.1 \\
3325 & 20.8 & 57.8 & 10.7 & 7.7 \\
3300 & 20.5 & 48.9 & 9.1 & 7.6 \\
3275 & 22.2 & 37.4 & 6.9 & 8.2 \\
3250 & 20.2 & 36.9 & 6.8 & 7.4 \\
\hline
\end{tabular}

a Depth of top of insulated cable below rig floor (see Fig. 1).

within the cased (sediment) section of the hole. There is no large shift in the apparent resistivity for these measurements, although a gradual perturbation would be difficult to detect and theoretically could occur (Francis, 1981).

Apparent resistivities vary between about 7 and 16 $\mathrm{ohm}-\mathrm{m}$, a maximum in resistivity being reached at about 600 meters below sea floor. Lower values are found in the upper basement section, and near the bottom of the drilled section (7-9 ohm-m) between 700 and 800 meters below the sea floor ( $\sim 500 \mathrm{~m}$ depth in basement).

At Hole 504B a series of standard logs were run, including the laterolog (LL-3). This is an electrical log which geometrically focuses the current into a horizontal sheet and thereby provides a measure of the resistivity a few hole-diameters distant from the tool (Doll, 1951). Although with depth this log shows a high-amplitude variations in apparent resistivity, probably associated with local variations in lithology and porosity, the depth profiles filtered appropriately to compare with the electrode spacings of the large-scale experiment are remarkably similar (Figs. 4 and 5).

However, analogous to the comparison observed by Francis (1981) with the induction log on DSDP Leg 60, the large-scale experiment data shows significantly lower resistivity, by approximately a factor of 2 . Part of this difference at Hole 504B may be attributable to perturbations caused by the drilling itself-both physical

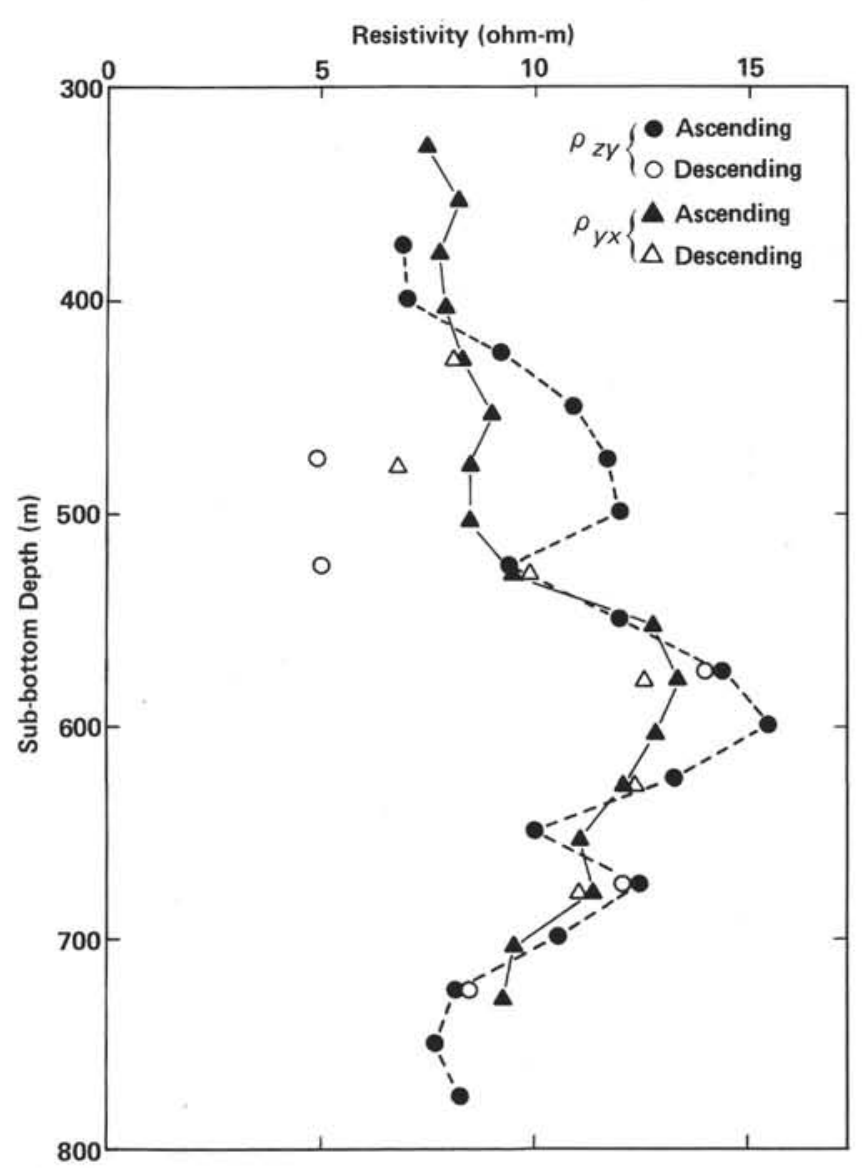

Figure 3. Apparent resistivity versus depth below sea floor from the large-scale experiment. Lines connect the values measured during the ascending phase of the experiment.

disturbance to the rock and temperature perturbations around the hole.

\section{INTERPRETATION}

\section{Comparison of Large-Scale and Laterolog Resistivity}

Since the laterolog gives apparent resistivities which are consistently higher than the large-scale resistivities by approximately a factor of 2 , we must sort out differences which may be caused by these different measurement techniques:

1) Because the cable was handled carefully and checked both before and after the Leg 70 large-scale experiment, the preferred explanation of Francis (1981) for the Leg 60 large-scale experiment, in terms of cable insulation damage causing leakage of current, does not appear to be viable for Leg 70 .

2) The physical disturbance of drilling might be expected to fracture, and hence increase the porosity of, rock nearby the drill hole. Such fracturing would tend to decrease its resistivity, opposite to the observed differences between the laterolog (most sensitive to rock near the hole) and the large-scale measurements. No major effects of physical disturbances to the drilled rock were seen in crustal drilling of the Mid-Atlantic Ridge on DSDP Leg 46 (Kirkpatrick, 1979). However, it is 


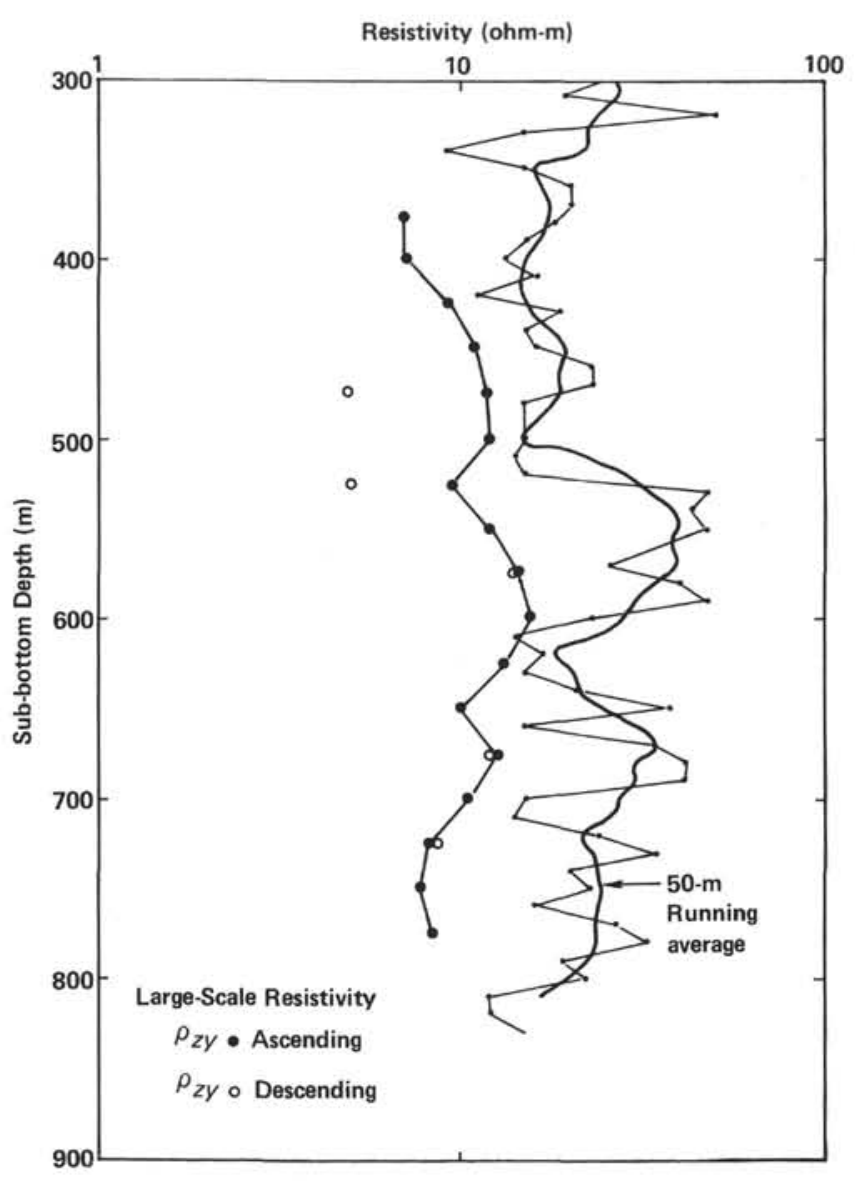

Figure 4. Apparent resistivity versus depth for the large-scale experiment $\left(\varrho_{z y}\right)$ and for that determined by standard logging (laterolog, LL-3), which is averaged by eye over 10-meter intervals, and then numerically as a 50-meter running average (thick-lined curve).

also possible that rock powder caused by drilling might decrease the porosity of rock around the hole, particularly if there were any tendency for water to flow from the hole into the rock. The circulation of water during drilling produces pressure gradients which would favor such flow. The increased resistivity in the laterolog data between about 300 and 350 meters depth (Fig. 2), where flow is apparently entering an underpressured zone of normally porous pillow basalts (Becker et al., this volume), may represent such an effect. Nevertheless, it seems rather unlikely that the consistent difference between the large-scale and laterolog resisitivities throughout the basalt section has such an explanation.

3) The resistivity differences may be due in part to the differences between scales of the measurement techniques and that of the actual resistivity variability (suggested by C. Cox). If we assume that the resistivity variations are due to variations in porosity, we can express their dependence on each other from Archie's (1942) law:

$$
\sigma_{r}=C \sigma_{w} p^{n},
$$

where $\sigma_{r}$ is the measured electrical conductivity, $\sigma_{w}$ is the electrical conductivity of pore fluid, and $p$ is the mean

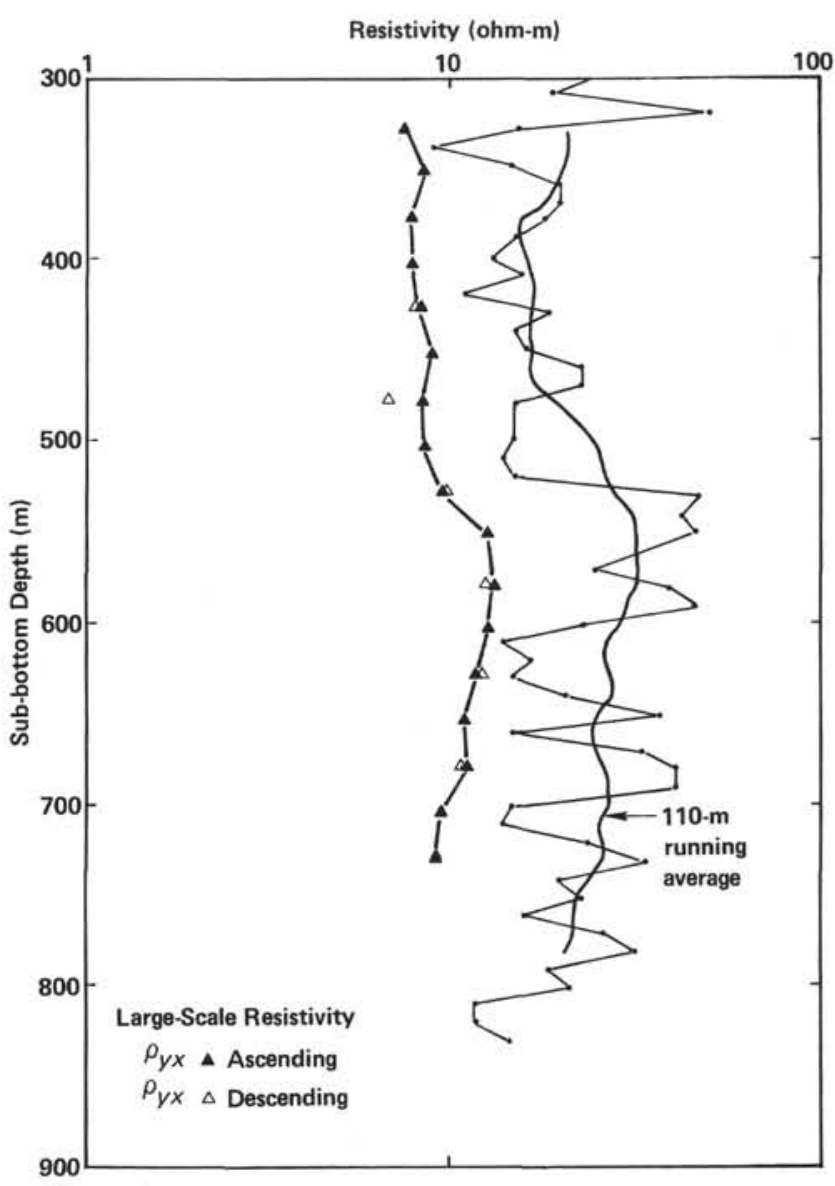

Figure 5. Same as Figure 3 for $\varrho_{y x}$. Running average of standard log is taken over 110-meter intervals.

porosity. $C$ is a non-dimensional constant with a value typically close to 1 , and the exponent $n$ commonly is about 2 for sedimentary rocks. Archie's law has not been extensively investigated for igneous rock, but the data for the ocean crust indicate the validity of the functional relationship with an uncertain exponent (Kirkpatrick, 1979).

If the porosity variations occur at a smaller scale than the measurements of electrical conductivity, then the local variation in conductivity $\sigma_{1}$ should be averaged as

$$
\int^{V} \frac{\left(\sigma_{1}\right)^{1 / n} \mathrm{~d} V}{V}
$$

to give the relevant large-scale conductivity mean. For $n=2$, the large-scale conductivity thus should be calculated as the mean square root of the small-scale conductivity element values, rather than the simple mean of these elements. The former would tend to bring the laterolog and large-scale conductivity profiles (Figs. 4 and 5) into closer agreement. It obviously would not eliminate the discrepancy, however, because the 10-meter mean values of the laterolog do not overlap those of the large-scale experiment. It seems unlikely that even greater variability on a scale smaller than 10 meters would bring the two methods into agreement. 
4) The measured conductivity is strongly affected by the conductivity of the fluid (sea water) filling the pores in the rock, as well as the porosity itself. The conductivity of sea water is a function of both pressure and temperature, and the latter is by far the largest effect at Hole 504B. In the laboratory, the conductivity of sea water has been measured only up to temperatures of about $35^{\circ} \mathrm{C}$ (Horne and Frysinger, 1963; Bradshaw and Schleicher, 1980), with the result that its conductivity is approximately doubled between 0 and $30^{\circ} \mathrm{C}$. The highest temperature over the drilled depth at Hole 504B is estimated at $120^{\circ} \mathrm{C}$, although the drilling itself substantially reduced the temperatures in the hole by the circulation of drilling fluid (sea water) at lower temperatures. The transient temperatures caused by drilling will be propagated by conduction to some distance (a few meters) from the hole, such that its effects will be seen primarily by the laterolog, rather than the large-scale experiment. Hence, the effect of cooling near the hole should cause the laterolog to measure higher resistivities, as observed.

In the following we attempt to evaluate quantitatively the effects of these temperature perturbations and calculate the porosities deduced from the measurements of electrical conductivity.

\section{Temperature Effects and Porosity}

The effects of heat conduction around the hole can be easily calculated from the time/depth history of the drill hole and the temperature disturbance associated with the drilling. The latter disturbance is primarily the effect of circulating sea water, used to facilitate drilling, of different temperature in the hole. For most deep-sea drill holes, this circulating water will have a temperature close to that of deep ocean water, although hiatuses in drilling (as a result of coring operations, equipment breakdowns, etc.) and the exchange of heat through the drill pipe and bore-hole walls create more-complex boundary conditions (Burch and Langseth, 1981). In addition, as discussed briefly above, some water may be advected through the bore-hole walls by pressure gradients, so that conduction theory may not be entirely adequate.

As a first approximation, we assume that the bore hole is maintained at deep-sea-water temperature $\left(2^{\circ} \mathrm{C}\right)$ during drilling, and we use conduction theory to estimate the region of disturbed temperatures around the hole (Carslaw and Jaeger, 1959). For cylindrical geometry around a line source, the radius $a$ of the disturbed zone is given approximately as $2(\alpha t)^{1 / 2}$, where $\alpha$ is thermal diffusivity and $t$ is time. For $\alpha=3 \times 10^{-3} \mathrm{~cm}^{2} / \mathrm{s}$, the following table gives the radii of the disturbed zone at different times:
A closer approximation might include adding the radius of the hole $(\sim 15 \mathrm{~cm})$ to the above disturbed zone radii, to account for the boundary condition at the bore-hole wall.

The upper part of the basalt section (down to $489 \mathrm{~m}$ below sea floor) of Hole 504B was drilled on Leg 69, about 50 to 60 days before down-hole measurements on Leg 70. The disturbed zone for this section of the hole should extend to a radius of 2 meters or more. The time of disturbance for the remainder of the hole drilled on Leg 70 before down-hole measurements ranged from 2 days at the bottom to about 12 days at the top of the drilled section. Therefore, radii of disturbance for this section should be about 0.5 meters to somewhat greater than 1 meter.

If the laterolog measures primarily the conductivity of the disturbed (cooled) material around the hole, whereas the large-scale experiment emphasizes the conductivity of material farther away, subject to the existing geothermal gradient, we can calculate two different sets of porosities for comparison. We assume that the pore fluid is sea water, and that at large distances from the bore hole (a few meters or more) its temperature is given by the equilibrium geothermal gradient, but that near the bore hole it has been disturbed thermally by the drilling, as discussed above. The equilibrium gradient has been calculated from temperature logging and measurements in the sediments (Becker et al., this volume). Temperatures near the bore hole are assumed to be those measured by the temperature log of 16 December 1979, immediately before the large-scale resistivity experiment. These temperatures over the measured basalt section of Hole 504B are given at 25-meter depth intervals in Table 2. Equilibrium temperatures exceed those measured in the hole on 16 December by about $15^{\circ} \mathrm{C}$ near the bottom of the drilled hole, to more than $50^{\circ} \mathrm{C}$ near the top of the basalt section.

Table 2. Estimated basement temperatures at Hole 504B.

\begin{tabular}{ccc}
\hline $\begin{array}{c}\text { Sub-bottom } \\
\text { Depth } \\
\text { (m) }\end{array}$ & $\begin{array}{c}\text { Bore-Hole } \\
\text { Temperature, } \\
\text { 16 Dec. 1979 }\end{array}$ & $\begin{array}{c}\text { Equilibrium } \\
\text { Temperature }\end{array}$ \\
\hline 300 & 9.5 & - \\
325 & 10.5 & 63.0 \\
350 & 19.5 & 65.8 \\
375 & 30.0 & 68.7 \\
400 & 45.5 & 71.5 \\
425 & 50.5 & 74.3 \\
450 & 55.0 & 77.2 \\
475 & 57.7 & 80.0 \\
500 & 59.7 & 82.9 \\
525 & 63.5 & 85.7 \\
550 & 66.4 & 88.6 \\
575 & 68.7 & 91.4 \\
600 & 71.3 & 94.3 \\
625 & 73.7 & 97.1 \\
650 & 77.7 & 100.0 \\
675 & 81.7 & 102.8 \\
700 & 84.6 & 105.7 \\
725 & 89.1 & 108.5 \\
750 & 93.5 & 111.4 \\
775 & 99.6 & 114.2 \\
800 & 105.8 & - \\
\hline
\end{tabular}


As just mentioned, the electrical conductivity of sea water has been measured only up to about $35^{\circ} \mathrm{C}$. The conductivity of sea water with a salinity of that near the bottom at Hole 504B ( $S=34.7 \%$; Laird, 1971) is about $3 \mathrm{Sm}^{-1}$ at $0^{\circ} \mathrm{C}$, and is approximately twice that at $30^{\circ} \mathrm{C}$ (Horne and Frysinger, 1963; Bradshaw and Schleicher, 1980). We assume a linear relationship of conductivity versus temperature, given by

$$
\sigma_{w}=3+\frac{T\left({ }^{\circ} \mathrm{C}\right)}{10} S m^{-1},
$$

to calculate the pore-water conductivities corresponding to the temperatures of Table 2 . The conductivities at the highest temperatures are greater by more than a factor of 4 than that at $0^{\circ} \mathrm{C}$, an increase which is confirmed experimentally on dilute $\mathrm{NaCl}$ solutions (Quist and Marshall, 1968).

We have calculated porosities according to Archie's law (Eq. 2), where we initially take $n=2$, a typical value for equidimensional, randomly connected pore spaces. Hyndman and Drury (1976) found a relatively high exponent of about 2.5 on ocean-crust basalt samples in the laboratory, but the exponent for fractured porous crust would be expected to be lower. The results for both the laterolog and the large-scale experiment are graphed in Figure 6A. These results show a porosity generally decreasing with depth, from about 10 to $12 \%$ in the upper basalt section to about 6 to $8 \%$ in the lower. Most of the decrease is in the upper 200 to 250 meters, with little apparent change below that level. A maximum in apparent resistivity at mid-depths (Figs. 4 and 5) is not reflected in a minimum in porosity, because of the compensating effect of the temperature gradient.

The temperature disturbances of drilling apparently do not account entirely for the differences in apparent resistivity between the laterolog and large-scale data. The laterolog gives systematically lower values of porosity, corresponding to its higher apparent resistivity, although the differences $(2-3 \%)$ are small and may not be significant. We also note that the correlation between the laterolog and large-scale experiment porosity, particularly $P_{z y}$, would be improved if the latter were shifted upward by 20 to 30 meters. This may indicate the bias in assigning the depth of the large-scale electrode array to that of the lowermost potential electrode; it may be more correct to designate the depth of the midpoint of the electrode array.

\section{Discussion}

The possible difference in porosity near and far from the drill hole, as measured by the laterolog and largescale experiments, respectively, may have several causes. First, we should acknowledge that these differences may be instrumental. The laterolog was provided under contract from an oil-field logging company. In oil-well logging, most emphasis is placed on the measurement of differences in resistivity down-hole, rather than determining the absolute value of resistivity. Hence no calibration standards were employed to check absolute values during the field measurements. Similarly, faulty equipment could cause errors in the measurement of the large-scale resistivity, although the electrical checks and monitoring of this relatively simple experiment indicate to us a low probability of significant bias.

Secondly, the lower calculated porosities near the hole may be the result of drilling disturbances (in addition to temperature effects). The possible effect of drill cuttings, which can fill the pore spaces of rock around the hole, has been discussed above. A similar effect would be observed if the pore fluids far from the hole had a higher salinity (and hence higher conductivity) than the pore fluids near the hole. The chlorinity data for in situ sampled pore waters at Site 504 do not indicate any large difference in salinity of pore waters from nearbottom sea water (Mottl, Anderson, et al., this volume), although slightly different than for surface sea water which has been pumped down-hole during drilling. The salinity differences are much smaller than those required to account for the measured electrical-conductivity differences.

Finally, the porosity differences may be explained by the use of an inappropriate exponential factor in Archie's relationship. If an exponent of 1.8 , rather than 2 , is assumed for the large-scale data, the calculated porosities are nearly the same as given by the laterolog data throughout the basalt section (Fig. 6B). There is evidence that the exponential factor for ocean-crust basalts may depend on the scale of the measurements. By relating electrical conductivity and porosity, Hyndman and Drury (1976) obtained a factor of about 2.5 for handsized specimens, whereas Kirkpatrick (1979) deduced a low value of about 1.3 from logging data. Cann and Von Herzen (this volume) obtained a value of about 2.1 from logging data in Hole 504B. High values may reflect a lack of connected porosity, and low values an increase of the connected porosity in the form of thin sheets (faults); these different porosity models may be applicable at different scales in the ocean crust. On the other hand, the observed differences in the exponential factors may reflect the amount of clay mineralization (alteration) of the basalts. In any case, an exponent of 1.8 in Archie's relationship does not seem unreasonable for the large-scale data (tens to hundreds of meters); whether a different exponent is appropriate at scales of meters or less seems still an open question.

An interesting result of these calculations is that the upper section of the ocean crust at Hole 504B shows relatively higher porosity, decreasing gradually with depth over several hundred meters by approximately a factor of 2. Below that, porosity is rather uniform to the maximum depth drilled ( $562 \mathrm{~m}$ into basalt). A relatively high porosity ( $10 \%$ or greater) for the upper basalt section and mean porosities less than $10 \%$ for the lower section also are deduced from the neutron porosity log (Cann and Von Herzen, this volume). Supporting data for this porosity structure were obtained from an oblique seismic experiment at Hole 504B (Stephen, this volume), indicating increasing velocity with depth in the crust. The upper drilled section is dominated by pillow basalts, with characteristically high porosity, whereas the lower section ( $>500 \mathrm{~m}$ below sea floor) contains many massive 

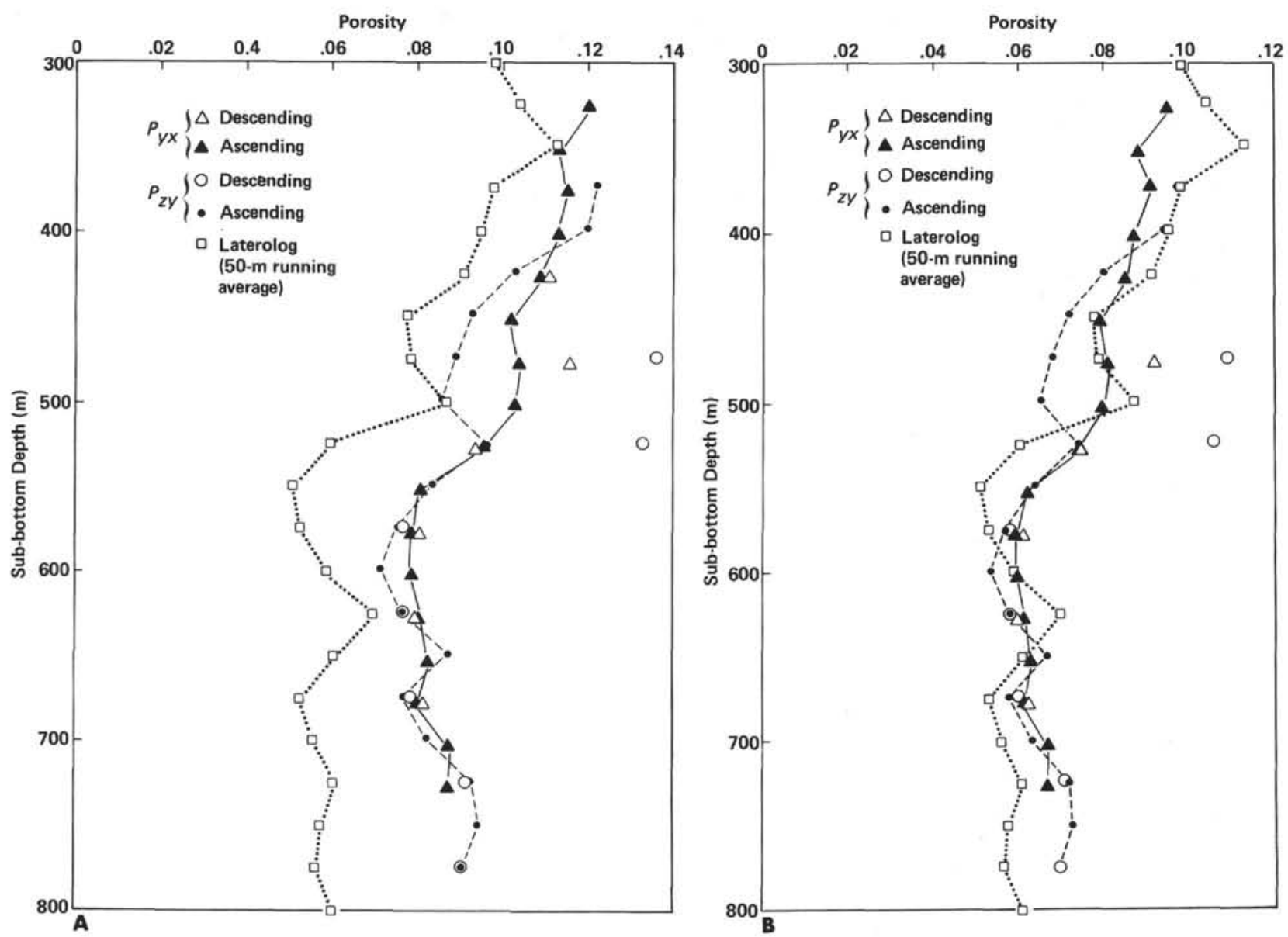

Figure 6. A. Porosity versus depth, calculated from Archie's relationship (Eq. 2 ) with exponent $n=2$, using the data of Tables 1 and 2 and the functional form of temperature dependence of sea-water conductivity given by Equation 4. Bore-hole temperature column of Table 2 applied to laterolog and equilibrium temperatures to large-scale data (see text). B. Same as $6 \mathrm{~A}$, except exponent $n=1.8$ used in Archie's relationship (Eq. 2) for large-scale data.

basalt flows with very low porosity. The approximate similarity of the large-scale mean porosities determined by different methods is reassuring.

\section{CONCLUSIONS}

Excellent data have been obtained from a down-hole experiment at Hole 504B, near the Costa Rica Rift, on large-scale electrical conductivity of in situ upper oceanic crust. The principal results of this study over a vertical section of more than 500 meters of 6-m.y.-old ocean crust are as follows:

1) Apparent resistivity ranges between 7 to $16 \mathrm{ohm}$ $\mathrm{m}$, the maximum occurring near 375 meters below the upper surface of the crustal rocks;

2) The resistivity measured by standard electrical logging (laterolog LL-3) has the same form with depth, but with values about a factor of 2 lower than those of the large-scale experiment;

3) When the effects of the environment, primarily temperature, are fully considered, the resistivity maximum does not correspond to a porosity minimum at middle depths;

4) Calculated porosities are comparable between the large-scale and logging measurements, when the effects of drilling on temperatures near the hole are taken into account;

5) Porosity in the upper 250 meters is about $10 \%$, decreasing to 5 to $8 \%$ between 250 and 500 meters. These values are comparable to those independently determined from down-hole neutron logging.

\section{ACKNOWLEDGMENTS}

We are grateful to the DSDP technical staff, and the officers, crew, and drilling teams on the Glomar Challenger for the expertise which made this experiment possible. Paul Laughlin of DSDP gave valuable assistance with the instrumentation and operation of the large-scale experiment. R. Stephen (WHOI) and C. Cox (SIO) reviewed the manuscript and gave valuable advice. R. V. H. derived support from NSF grant OCE-19324 during data analysis and preparation of this paper. Woods Hole Oceanographic Inst. Contribution No. 4987.

\section{REFERENCES}

Anderson, R. N., Langseth, M. G., and Sclater, J. G., 1977. The mechanisms of heat transfer through the floor of the Indian Ocean. J. Geophys. Res., 82:3391-3409.

Archie, G. E., 1942. The electrical resistivity $\log$ as an aid in determining some reservoir characteristics. J. Petrol. Tech., 5:1-8.

Bradshaw, A. L., and Schleicher, K. E., 1980. Electrical conductivity of sea water. IEEE J. Ocean. Eng., OE-5:50-62. 
Burch, T. K., and Langseth, M. G., 1981. Heat-flow determination in 3 DSDP boreholes near the Japan trench. J. Geophys. Res., 86:9411-9419.

Carslaw, H. S., and Jaeger, J. C., 1959. Conduction of Heat in Solids: New York (Clarendon Press).

Doll, H. G., 1951. The laterolog. J. Petrol. Tech., 14:7.

Francis, T. J. G., 1981. Large scale resistivity experiment at Hole 459B. In Hussong, D., Uyeda, S., et al., Init. Repts. DSDP, 60: Washington (U.S. Govt. Printing Office).

Green, K. E., Von Herzen, R. P., and Williams, D. L., 1981. The Galapagos spreading center at $86^{\circ} \mathrm{W}$ : a detailed geothermal field study. J. Geophys. Res., 86:979-986.
Horne, R. A., and Frysinger, G. R., 1963. The effect of pressure on the electrical conductivity of sea water. J. Geophys. Res., 68:19671973.

Hyndman, R. D., and Drury, M., 1976. The physical properties of oceanic basement rocks from deep drilling on the mid-Atlantic ridge. J. Geophys. Res., 81:4042-4052.

Kirkpatrick, R. J., 1979. The physical state of the oceanic crust: results of downhole geophysical logging in the mid-Atlantic ridge at $23^{\circ} \mathrm{N}, J$. Geophys. Res., 84:178-188.

Laird, N. P., 1971. Panama Basin deep water-properties and circulation. J. Mar. Res., 29:226-234.

Quist, A. S., and Marshall, W. L., 1968. Electrical conductances of aqueous sodium chloride solutions from 0 to $800^{\circ}$ and at pressures to 4000 bars. J. Phys. Chem., 72:684-703. 